\title{
Hubungan Pola Asuh Orangtua terhadap Kejadian Obesitas pada Anak Usia Sekolah
}

\author{
Komang Yogi Triana ${ }^{1 *}$, N.M Pande Lilik Lestari², N.M Ririn Anjani ${ }^{3}$, \\ N.P Pristha Dewi Y. ${ }^{4}$ \\ ${ }^{1,2,3,4}$ Program Studi Profesi Ners STIKES Bina Usada, Bali, Indonesia \\ *yogitriana25@gmail.com
}

\begin{abstract}
Obesity had known as a condition of excessive levels of fat in a person's body which is can result in the emergence of chronic diseases. Currently the problem of obesity has been experienced by many children. One of the main actions to deal with obesity on childhood is through the closest person, they were the family. This study aimed to determine the relationship of parenting style applied by parents to the incidence of children obesity that occurs in the elementary school of Badung Regency, Bali Province. The research method in this research was crossectional study with a total sampling technique. This research was conducted at two elementary school in Badung Regency involving 96 students from grades 5 and 6 . The analysis of this study used the Chi Square test which shows the results of $p$ value $=0.03<\alpha$. It means that there was a significant relationship between parenting style to the incidence of obesity in school-age children in the Badung regency. Thus, parents are expected to be able to apply good parenting style by not being too permissive or forcing children in order to build the character of children and support proper nutritional status according to the child's age.
\end{abstract}

Keywords: parenting style, obesity, school age children

\begin{abstract}
Abstrak
Obesitas dikatakan sebagai suatu kondisi kelebihan kadar lemak dalam tubuh seseorang yang tertimbun dalam jaringan subkutan yang dapat mengakibatkan munculnya penyakit kronis. Saat ini masalah obesitas bahkan sudah banyak dialami oleh anak-anak. Salah satu tindakan utama untuk menangani obesitas pada usia anak adalah melalui orang terdekatnya yaitu keluarga. Masing-masing keluarga pada umumnya, menerapkan bentuk pola asuh yang berbeda-beda. Penelitian ini bertujuan untuk mengetahui hubungan dari pola asuh yang diterapkan orangtua terhadap kejadian obesitas yang terjadi di lingkungan sekolah dasar wilayah Kabupaten Badung, Provinsi Bali. Metode penelitian dalam penelitian ini adalah crossectional study dengan teknik pengambilan sampel total sampling. Penelitian ini dilakukan di 2 SD di wilayah Badung dengan melibatkan 96 siswa yang berasal dari kelas 5 dan 6 SD. Analisis penelitian ini menggunakan uji chi square yang menunjukkan hasil $\mathrm{p}$ value $=0,03<$ $\alpha$, yang berarti bahwa terdapat hubungan yang signifikan antara pola asuh yang diterapkan orangtua terhadap kejadian obesitas pada anak usia sekolah di wilayah kabupaten Badung. Dengan demikian, orangtua diharapkan dapat menerapkan pola asuh yang baik dengan tidak terlalu bersikap permisif atau pun memaksa anak untuk membentuk karakter anak dan menunjang status gizi yang tepat sesuai usia anak.
\end{abstract}

Kata kunci: pola asuh, obesitas, anak usia sekolah 


\section{PENDAHULUAN}

Pada abad ke-21 ini, salah satu masalah yang menjadi tantangan kesehatan paling serius bagi masyarakat dunia adalah obesitas pada anak. Masalah ini menjadi masalah global dan berdampak terhadap banyak negara dengan penghasilan rendah dan menengah, terutama bagi masyarakat yang tinggal di daerah perkotaan. Prevalensi dari kejadian obesitas pada anak pun telah meningkat pada tingkat yang mengkhawatirkan banyak pihak. Pada tahun 2016, jumlah anak yang mengalami kelebihan berat badan saat mereka masih berusia di bawah lima tahun, diperkirakan berjumlah lebih dari 41 juta anak. Hampir setengah dari semua anak yang mengalami kelebihan berat badan tersebut (usia di bawah 5 tahun) tinggal di negara-negara Asia dan seperempatnya tinggal di Benua Afrika (World Health Organization [WHO], 2018). Studi deskriptif lainnya pada tahun 2016 oleh Suryamulyawan \& Arimbawa (2019) juga mengungkapkan bahwa kondisi obesitas juga banyak ditemui pada anak usia sekolah, yaitu sebesar $17,2 \%$ anak usia sekolah di kota Denpasar mengalami obesitas dan 18,2\% tergolong memiliki berat badan berlebih (overweight).

Pola makan yang kurang tepat dapat menjadi penyebab dari munculnya masalah nutrisi pada anak. Masyarakat saat ini cenderung lebih menyukai makanan cepat saji (fast food) dan berbagai makanan dan minuman olahan dengan kadungan gula yang tinggi (Gaziano, 2010; Centers for Disease Control and Prevention [CDC], 2011). Selain itu, ada juga bukti yang mendukung bahwa asupan gula berlebihan dengan minuman ringan, peningkatan ukuran porsi makan, dan penurunan aktivitas fisik secara terus-menerus telah memainkan peran penting dalam peningkatan angka obesitas di seluruh dunia. Obesitas pada masa kanak-kanak dapat sangat memengaruhi kesehatan fisik, sosial, dan emosi anak, serta harga dirinya. Hal ini juga dikaitkan dengan hasil akademik yang buruk dan kualitas hidup yang lebih rendah yang dapat dialami oleh anak dengan obesitas (Sahoo et al., 2015).

Anak-anak dengan kelebihan berat badan atau obesitas pada usia dini, cenderung tetap dengan obesitasnya hingga memasuki usia dewasa dan besar kemungkinan mengalami Penyakit Tidak Menular (PTM) pada usia yang lebih muda, salah satu contohnya penyakit diabetes atau gangguan kardiovaskuler (Triana, 2016). Meskipun demikian, masih banyak masyarakat dan orangtua yang berpendapat bahwa anak dengan postur tubuh gemuk adalah anak sehat, sehingga banyak orangtua yang merasa bangga melihat anak-anak mereka dengan postur tubuh yang besar (gemuk) (Soetjiningsih, 2014).

Kegemukan dan obesitas sebagian besar dapat dicegah. Karena itu pencegahan obesitas pada masa kanak-kanak seharusnya menjadi prioritas utama (WHO, 2018). Pada tahun 2015-2016, CDC mencatat prevalensi kejadian obesitas pada anak yang berusia 6 hingga 11 tahun mencapai $18,4 \%$, usia remaja mencapai $20,6 \%$ dan usia anak pra sekolah mencapai 13,9\% di United States (CDC, 2017). Pada tahun 2013, data di riset kesehatan dasar (Riskesdas) Indonesia menunjukkan prevalensi obesitas yang terjadi pada anak usia sekolah yaitu 5-12 tahun mencapai $8,8 \%$, dengan prevalensi paling tinggi diduduki oleh DKI Jakarta yang mencapai angka $30,1 \%$. Terdapat 15 provinsi di 
Indonesia yang memiliki prevalensi anak sangat gemuk di atas prevalensi nasional yang tersebar hampir di semua pulau besar Indonesia, salah satunya Provinsi Bali yang masuk dalam 10 provinsi teratas dengan kejadian obesitas pada anak yang tinggi (Kemenkes RI, 2013). Bahkan menurut WHO (2011), 1 dari 10 anak di dunia tergolong mengalami kegemukan (obesitas).

Tingginya kasus obesitas pada anak serta permasalahan kesehatan yang dapat ditimbulkannya menyebabkan situasi ini menjadi salah satu prioritas utama dunia dalam upaya peningkatan kualitas kesehatan suatu negara, yaitu dalam bentuk tindakan pencegahan dan penatalaksanaan kasus obesitas, khususnya pada anak (CDC, 2011; World Health Organization [WHO], 2015). Suatu upaya preventif telah disusun terkait masalah obesitas pada masa anakanak. Upaya ini menyasar hampir di semua tingkatan, baik anak sebagai individu, namun juga lingkungan keluarga. Lingkungan keluarga khususnya para orang tua menjadi pihak yang paling berpengaruh dalam perkembangan kesehatan anak-anak, terutama terkait dengan penerapan gaya hidup anak-anak, termasuk pola makan anak (Young, Northern, Lister, Drummond, \& O'Brien, 2007 dalam Jang, 2015). Penerapan gaya hidup yang ditumbuhkan di lingkungan keluarga tidak akan terlepas dari pola asuh yang diterapkan orangtua untuk anak. Hal inilah yang dapat membentuk karakter dan kebiasaan anak dalam kesehariannya, termasuk dalam membentuk kebiasaan makan anak yang berimbas pada status nutrisi anak.
Penelitian ini bertujuan untuk mengidentifikasi adanya hubungan pola asuh dari orangtua terhadap kejadian obsesitas yang dialami oleh anak.

\section{METODE}

Penelitian ini menggunakan desain deskriptif korelasional dengan rancangan cross-sectional. Populasi yang dalam penelitian ini adalah seluruh anak sekolah yang ada di lingkungan 2 SD wilayah Badung. Setiap anak-anak yang bersedia terlibat dalam penelitian ini dilakukan penimbangan berat badan dan pengukuran tinggi badan. Selanjutnya, berdasarkan data tersebut dicari IMT masing-masing anak dengan membagi berat badan dalam kilogram dengan tinggi badan anak dalam meter kuadrat. Nilai yang didapat disebut dengan IMT. IMT yang didapatkan untuk masing-masing anak, lalu disesuaikan dengan tabel Standar Antropometri Penilaian Status Gizi Anak yang ditetapkan oleh Kementerian Kesehatan Republik Indonesia berdasarkan ketetapan perhitungan antropometri anak dari WHO. Anak yang dinyatakan mengalami obesitas adalah anak dengan IMT kategori > 2 SD (Standar Deviasi), sedangkan anak dengan IMT kurang dari 2 SD yaitu antara $>1$ SD sampai dengan 2 SD masih digolongkan anak dengan berat badan lebih (gemuk).

Penelitian ini dilakukan pada Bulan JuniJuli tahun 2019 yang melibatkan 96 responden sesuai dengan kriteria penelitian yaitu dengan teknik sampling Total Sampling sehingga seluruh populasi yang memenuhi kriteria dilibatkan dalam penelitian ini. Instrumen pada penelitian ini menggunakan Parental Authority Questionaire yang terdiri dari 20 item pertanyaan mengenai pola asuh yang 
diterapkan orangtua kepada anak dengan menggunakan skala likert dan lembar observasi menggunakan Kurva IMT anak usia sekolah dari Kementerian Kesehatan Republik Indonesia, dan data yang diperoleh dianalisis dengan uji Chi Square. Penelitian ini telah mendapatkan persetujuan laik etik dari Komisi Etik Penelitian Bina Usada Bali dengan nomor 314/EA/KEPK-BUB-2019.

\section{HASIL}

\section{Karakteristik Responden}

Karakteristik dari responden yang dilibatkan dalam penelitian ini dideskripsikan berdasarkan jenis datanya. Data numerik yaitu usia, berat badan, tinggi badan, Indeks Masa Tubuh (IMT) dan kelas yang dijelaskan melalui data mean, median, dan standar deviasi. Pada variabel data kategorik yaitu jenis kelamin, status pekerjaan ibu, pola asuh, kejadian obesitas disajikan dalam bentuk distribusi frekuensi dan persentase.

Tabel 1. Distribusi Frekuensi Responden berdasarkan Usia, Jenis Kelamin, dan Status Pekerjaan Ibu Tahun $2019(n=96)$

\begin{tabular}{ccc}
\hline Karakteristik & Frekuensi & $\begin{array}{c}\text { Persentase } \\
(\%)\end{array}$ \\
\hline Umur (tahun) & 26 & 27,1 \\
10 & 61 & 63,5 \\
11 & 9 & 9,4 \\
12 & & \\
Jenis kelamin & 47 & 49,0 \\
Laki-laki & 49 & 51,0 \\
Perempuan & & \\
Status bekerja ibu & 77 & 80,2 \\
Bekerja & 19 & 19,8 \\
Tidak bekerja &
\end{tabular}

Berdasarkan tabel 1, lebih dari setengah responden dalam studi ini berusia 11 tahun yaitu sebanyak 61 orang, dimana responden perempuan lebih banyak dibandingkan laki-laki yaitu sebanyak 49 orang. Jika dilihat dari karakteristik status pekerjaan ibu, sebagian besar ibu responden bekerja dengan jumlah mencapai 77 orang.

\section{Tabel 2. Distribusi Frekuensi Responden berdasarkan Pola Asuh Orangtua dan Kejadian Obesitas $(n=96)$}

\begin{tabular}{lcc}
\hline Variabel Independen & Frekuensi & $\begin{array}{c}\text { Persentase } \\
(\%)\end{array}$ \\
\hline Pola Asuh & & \\
Pola asuh baik & 46 & 47,9 \\
Pola asuh kurang & 50 & 52,1
\end{tabular}

Berdasarkan tabel 2 di atas, dapat dilihat perbandingan pola asuh baik dan pola asuh kurang yang diterapkan oleh orangtua tidak terlalu jauh, hanya selisih 4 angka dimana pola asuh baik sebanyak 46 orang dan pola asuh kurang sebanyak 50 orang.

Tabel 3. Distribusi Frekuensi Responden berdasarkan Status Obesitas $(\mathbf{n}=96)$

\begin{tabular}{ccc}
\hline Variabel Dependen & Frekuensi & $\begin{array}{c}\text { Persentase } \\
(\%)\end{array}$ \\
\hline Status Obese & 63 & 65,6 \\
Non obese & 33 & 34,4 \\
Obese & \\
\hline
\end{tabular}

Berdasarkan data pada tabel 3, dapat dilihat bahwa jumlah anak yang tidak mengalami obesitas lebih banyak daripada responden yang mengalami obesitas yaitu dengan IMT $<2$ SD sebanyak 63 orang.

Tabel 4. Gambaran rerata berat badan, tinggi badan, dan IMT responden $(n=96)$

\begin{tabular}{lcclc}
\hline $\begin{array}{l}\text { Karak- } \\
\text { teristik }\end{array}$ & Mean & Median & $\begin{array}{l}\text { Standar } \\
\text { Deviasi }\end{array}$ & Min-Max \\
\hline $\begin{array}{l}\text { Berat } \\
\text { badan }\end{array}$ & 45,14 & 43,4 & 12,76 & $22,8-74,6$ \\
$\begin{array}{l}\text { Tinggi } \\
\text { Badan }\end{array}$ & 142,4 & 144 & 7,54 & $124-163,5$ \\
IMT & 21,7 & 21,49 & 5,25 & $13-35$ \\
\hline
\end{tabular}


Berdasarkan tabel 4, terlihat bahwa berat badan tertinggi dari responden mencapai $74,6 \mathrm{~kg}$ dengan rerata berat badan rersponden mencapai 45,14 kg. Selain itu, pada karakteristik tinggi badan responden terlihat bahwa rerata tinggi badan responden mencapai $142,4 \mathrm{~cm}$ dengan tinggi badan tertinggi mencapai $163,5 \mathrm{~cm}$, sedangkan rerata Indeks Masa Tubuh (IMT) dari responden adalah 21,7 dengan IMT tertinggi mencapai 35. Berdasarkan IMT tersebut, rata-rata anak dalam penelitian ini belum termasuk dalam kategori obesitas yang ditentukan berdasarkan kurva IMT anak usia sekolah, dimana nilai 24 pada IMT menunjukkan kondisi obesitas pada anak.

\section{Hasil Analisis Bivariat}

Hasil analisis data bivariat menjelaskan mengenai hubungan antara dua variabel berdasarkan analisis data dengan uji komparatif tidak berpasangan (chi square). Adapun hasil analisis data tersajikan dalam tabel berikut:

Tabel 5. Hubungan Pola Asuh dengan Kejadian Obesitas pada Anak Usia Sekolah Tahun $2019(n=96)$

\begin{tabular}{llllll}
\hline $\begin{array}{l}\text { Variabel } \\
\text { Pola asuh }\end{array}$ & \multicolumn{2}{l}{ Status obesitas } & & & \\
\cline { 2 - 3 } & $\begin{array}{l}\text { Obe- } \\
\text { sitas (n) }\end{array}$ & $\begin{array}{l}\text { Non } \\
\text { Obesitas (n) }\end{array}$ & $\mathrm{X}^{2}$ & OR & $95 \%$ CI \\
\hline $\begin{array}{l}\text { Pola asuh } \\
\text { kurang }\end{array}$ & 23 & 27 & 0,022 & 3 & $23-7,5$ \\
$\begin{array}{l}\text { Pola asuh } \\
\text { baik }\end{array}$ & 10 & 36 & & & \\
\hline
\end{tabular}

Berdasarkan tabel 5 di atas, hasil analisis data dengan uji Chi Square dengan tingkat kemaknaan 0,05 menunjukkan bahwa $\mathrm{p}$ value $=0,022$ yang berarti $\mathrm{H}_{0}$ ditolak dan Ha diterima, sehingga dapat disimpulkan bahwa terdapat hubungan yang signifikan antara pola asuh dengan kejadian obesitas pada anak usia sekolah dengan $\mathrm{p}$ value < 0,05 (nilai $\mathrm{p}=0,022$ ) dan $95 \%$ CI tidak melewati angka 1.

Hasil analisis data juga menunjukkan bahwa nilai OR dari data tersebut adalah 3 yang berarti bahwa anak yang berada dalam lingkungan pola asuh kurang dapat berisiko 3 kali lebih besar mengalami obesitas dibandingkan anak dengan pola asuh baik.

\section{PEMBAHASAN}

Berdasarkan data pada hasil penelitian ini, sebagian besar responden responden duduk di kelas 5 dan 6 sekolah dasar dengan usia terbanyak adalah 11 tahun yaitu sebanyak 61 orang, dengan jenis kelamin perempuan mencapai 49 orang, angka ini lebih banyak dari laki-laki. Namun, jika dilihat dari karakteristik status pekerjaan ibu, sebagian besar ibu responden bekerja dengan jumlah mencapai 77 orang.

Karakteristik lainnya dapat dilihat dari gambaran berat badan anak, dimana berat badan tertinggi dari responden mencapai $74,6 \mathrm{~kg}$ dengan rerata berat badan P-r rerseponden mencapai 45,14 kg. Selain itu, pada karakteristik tinggi badan responden terlihat bahwa rerata tinggi badan responden mencapai $142,4 \mathrm{~cm}$ dengan tinggi badan tertinggi mencapai $163,5 \mathrm{~cm}$, 0,012angkan rerata Indeks Masa Tubuh (IMT) dari responden adalah 21,7 dengan IMT tertinggi mencapai 35. Angka IMT ini tergolong sudah melewati grafik +1 SD pada tabel antropometri IMT/U sehingga rerata responden dapat dikatakan mengalami berat badan yang berlebih (Kemenkes RI, 2011). Responden yang dikatakan obesitas adalah responden 
dengan IMT yang mencapai lebih dari 24 dengan titik kurva telah melebihi +2 SD. Kategori obesitas untuk anak usia sekolah, umumnya menggunakan grafik Indeks Masa Tubuh (IMT) yang disesuaikan dengan usia serta jenis kelamin anak lalu tentukan persentilnya, dimana persentil 8595 dikategorikan dalam berat badan gemuk dan untuk persentil > 95 anak digolongkan mengalami obesitas (Ogden, \& Flegal, 2010). Anak dengan obesitas dikatakan memiliki lemak tubuh yang berlebih dan sangat berisiko mengalami penyakit kronis seperti Diabetes atau penyakit jantung di usia muda (Ogden, \& Flegal, 2010; Sahoo et al., 2015).

Hasil penelitian ini menunjukkan adanya hubungan antara pola asuh dengan kejadian obesitas pada anak usia sekolah dengan $\mathrm{p}$ value $<\alpha(\mathrm{p}$ value $=0.012)$. Hal ini juga sejalan dengan hasil penelitian Boots, Tiggemann, Corsini, \& Mattiske (2015) yang menyatakan bahwa pola asuh yang berdampak pada strategi pemberian makan anak berpengaruh terhadap pola snacking anak yang akan terlihat dari status nutrisi anak. Namun hasil yang berbeda diungkapkan oleh Martha, Carbajal, \& López (2017) yang mendapatkan hasil bahwa tidak ada hubungannya pola asuh orangtua terhadap terjadinya obesitas pada anak. Hal ini dapat dipengaruhi oleh jumlah sampel yang dilibatkan atau terkait budaya setempat. Sedangkan penelitian yang dilakukan oleh Demir dan Bektas (2017) mendapatkan hasil bahwa ada hubungan antara pola pemberian makan dan pola asuh terhadap kejadian obesitas pada anak. Hal ini dikaitkan juga dengan dampak dari pola asuh orangtua terhadap respon kenyang dari anak saat diberikan makanan, sehingga semakin rendah respon kenyang anak maka akan meningkatkan risiko obesitas anak itu sendiri. Oleh karena itu, orang tua diharapkan dapat menerapkan pola asuh yang tepat untuk anak, khususnya dalam mengatur nutrisi anak. Hal ini jika dikaitkan dengan hasil penelitian ini, orangtua diharapkan dapat menunjukkan sikap yang tidak terlalu memaksa anak maupun permisif yang berlebihan. Diperlukan sikap yang tegas namun mendidik, agar anak dapat memahami mengenai pentingnya menjaga asupan gizi yang seimbang dan tidak berlebihan. Selain itu, kecepatan anak saat makan dikatakan tidak ada hubungannya dengan status obesitas anak, dimana cepat ataupun lambatnya cara anak dalam mengonsumsi sesuatu tidak selalu berdampak (Demir \& Bektas, 2017).

Kondisi obesitas yang terjadi pada masa anak-anak ini tidak dapat dipandang sebelah mata, dan perlu penanganan khusus. Perawat anak (pediatri) dengan perannya sebagai pemberi asuhan dan praktisi harus menjadigarda terdepan untuk dapat mengurangi angka obesitas pada anak. Salah satu keterampilan yang seharusnya perawat miliki adalah mampu mengidentifikasi pola asuh orangtua dan memberi edukasi mengenai pola asuh yang tepat diterapkan kepada anak, khususnya dari segi pembentukan pola makan anak (Grossklaus \& Marvicsin, 2014).

Sebuah komitmen atau prinsip dari individu untuk memefasilitasi kebutuhan anak baik fisik maupun psikologis disebut sebagai pola asuh. Baumrind (1991) menyatakan bahwa secara umum, terdapat 3 (tiga) tipe pola asuh orangtua dalam lingkungan keluarga, antara lain authoritarian, authoritative, dan permissive (Ashwill, 2014). Ketiga pola asuh ini memiliki karakteristiknya tersendiri dalam mengasuh 
anak. Pada tipe pola asuh authoritarian, orangtua umumnya akan memberikan aturan-aturan tertentu yang wajib dituruti oleh anak, sehingga anak seringkali menjadi kurang percaya diri. Berbeda halnya dengan pola asuh authoritative, pada tipe ini anak-anak menunjukkan harga diri yang tinggi dan terlihat lebih mandiri karena orangtua senantiasa menghargai pendapat anak-anaknya dan mengijinkan anak berbeda sesuai keinginannya. Tipe pola asuh yang terakhir adalah tipe permissive, dimana orangtua cenderung tidak memiliki kemampuan kontrol terhadap anak-anaknya. Hal ini sering berdampak pada munculnya sikap tidak menghargai dan agresif pada anak, namun di sisi lain anak dapat juga berkembang menjadi sosok yang kreatif dan spontan. Tipe pola asuh authoritative menjadi pilihan pola asuh yang dirasa terbaik untuk diterapkan pada anak, karena membentuk anak menjadi sosok yang mandiri namun tetap dalam pengawasan orangtua (Ashwill, 2014).

Berbagai penelitian menunjukkan betapa pentingnya peran orangtua dalam mencegah dan menangani kasus obesitas pada anak. Salah satu studi yang dilakukan oleh Thompson (2010) menjelaskan bahwa setiap orangtua sangat penting memahami bahwa risiko obesitas tidak hanya terjadi pada dewasa, melainkan juga pada anakanak, sehingga orangtua nantinya mampu mengimplementasikan pola asuh yang tepat bagi anak-anaknya dalam menangani obesitas. Salah satu metode yang dapat menjadi pilihan orangtua adalah dengan membatasi hadiah berupa makanan pada anak dan membuat aturan mengenai pola makan yang harus anak patuhi, baik di rumah maupun di tempat umum (Triana, 2016).
Hal ini seharusnya dapat menjadi perhatian perawat sebagai tenaga kesehatan dengan menerapkan peran edukator mengenai pola asuh yang tepat kepada orangtua sebagai upaya promotif agar dapat menerapkan pola asuh yang sesuai dengan kebutuhan anak, mengingat kondisi obesitas yang berlangsung lama dapat mengakibatkan munculnya berbagai penyakit kronis pada anak karena proses tumbuh kembang yang menjadi tidak optimal (Triana, 2016).

\section{KESIMPULAN}

Berdasarkan uraian di atas, maka dapat disimpulkan bahwa terdapat hubungan antara pola asuh terhadap kejadian obesitas pada anak usia sekolah di sekolah dasar wilayah Kabupaten Badung dengan nilai $p$ $<\alpha(\mathrm{p}=0,012)$. Responden yang terlibat dalam penelitian ini menunjukkan memiliki rerata berat badan yang berada di atas +1 SD (standar deviasi) dengan kategori berat badan lebih sesuai dengan grafik antropometri anak usia sekolah yang ditetapkan oleh Kementerian Kesehatan Republik Indonesia, dan pola asuh yang diterapkan orangtua terdiri dari pola asuh baik dan kurang.

Dengan demikian, perawat diharapkan dapat mengoptimalkan perannya sebagai edukator maupun konselor bagi orangtua untuk menerapkan pola asuh yang tepat dan dapat menjaga pola makan anak serta status nutrisi anak sejak dini dan tidak membiarkan anak dalam kategori obesitas hingga memasuki usia remaja. Salah satu caranya adalah melalui penerapan pola asuh yang tepat dengan menerapkan strategi makan dan strategi aktivitas yang tepat sesuai usia anak. 


\section{DAFTAR PUSTAKA}

Ashwill, J.N. (2013). Nursing care of children: Principles \& practice. (Fourth Edition). Missouri.

Centers for Disease Control and Prevention US Department of Health and Human Services. (2011). Overweight and obesity. Retrieved at :http://www.cdc.gov/obesity/index.html. (19 November 2015).

Boots, S. B., Tiggemann, M., Corsini, N., \& Mattiske, J. (2015). Managing young children's snack food intake. The role of parenting style and feeding strategies. Appetite, 92, 94-101. https://doi.org/10.1016/j.appet.2015.05.0 12.

Chung, A., Backholer, K., Wong, E., Palermo, C., Keating, C., \& Peeters, A. (2014). Trends in child and adolescent obesity prevalence according to socioeconomic position: protocol for a systematic review. Systematic Reviews, 3(1), 52. https://doi.org/10.1186/2046-4053-3-52.

Demir, D., \& Bektas, M. (2017). Eating behaviors the effect of childrens ' eating behaviors and parental feeding style on childhood obesity. Eating Behaviors, 26, 137-142.

https://doi.org/10.1016/j.eatbeh.2017.03. 004.

Grossklaus, H., \& Marvicsin, D. (2014). Parenting efficacy and its relationship to the prevention of childhood obesity. Pediatric Nursing, 40(2), 69-86. Retrieved from http://www.ncbi.nlm.nih.gov/pubmed/24 941509.

Jang, M. (2015). The family management style framework for families of children with obesity. Journal of Theory Construction \& Testing, 19(1), 5 .

Kementerian Kesehatan Republik Indonesia. (2011). Keputusan Menteri Kesehatan Republik Indonesia tentang Standar
Antropometri Penilaian Status Gizi Anak.

Kementerian Kesehatan Republik Indonesia. (2013). Riset kesehatan dasar: RISKESDAS 2013. Jakarta: Badan Penelitian dan Pengembangan Kesehatan Kementerian Kesehatan Republik Indonesia.

Martha, M., Carbajal, M., \& López, F. (2017). Parenting styles and their relation with obesity in children ages 2 to 8 years. Revista Mexicana de Trastornos Alimentarios, 8(1), 11-20. https://doi.org/10.1016/j.rmta.2017.01. 006.

Ogden, C. L., \& Flegal, K. M. (2010). Changes in terminology for childhood overweight and obesity. Age, 12(12).

Sahoo, K., Sahoo, B., Choudhury, A. K., Sofi, N. Y., Kumar, R., \& Bhadoria, A. S. (2015). Childhood obesity: Causes and consequences. Journal of family medicine and primary care, 4(2), 187.

Soetjiningsih. (2014). Tumbuh Kembang Anak. (Edisi kedua). Jakarta: EGC.

Suryamulyawan, K.A \& Arimbawa, I.M (2019). Prevalensi dan karakteristik obesitas pada anak sekolah dasar saraswati v kota denpasar tahun 2016. Intisari Sains Medis, 10(2). 342-346.

Thompson, M. E. (2010). Parental feeding and childhood obesity in preschool-age children: Recent findings from the literature. Issues in nursing. http://doi.org/10.3109/01460862.20 10.530057 .

Triana, K. Y. (2016). Manajemen obesitas dengan pola asuh efektif sebagai upaya preventif penyakit kronis pada anak. Jurnal Dunia Kesehatan, 5(1), 76789.

World Health Organization. (2015). Overweight and obesity. Retrieved from http://www.who.int/mediacentre/fa ctsheets/fs311/en/ (18 November 2015). 
World Health Organization. (2018). Taking action on childhood obesity report. Retrieved https://www.who.int/end-childhoodobesity/publications/taking-actionchildhood-obesity-report 


\section{HALAMAN INI SENGAJA DI KOSONGKAN}

